\title{
Analysis of Infrared Spectra of Neat Liquid N-Methylpyrrole
}

\author{
K.B. BEĆ* ${ }^{*}$ R. WIECZOREK, B. EydżBA-KopczyŃSKA AND J.P. HAWRANEK \\ Faculty of Chemistry, University of Wrocław, F. Joliot-Curie 14, 50-383 Wrocław, Poland
}

(Received December 11, 2012; in final form March 22, 2013)

The vibrational properties of neat liquid N-methylpyrrole were investigated. Quantitative near-infrared and mid-infrared spectra recordings including thin film MIR transmission studies were performed. Basing on these data the optical constants of N-methylpyrrole in the $12500-560 \mathrm{~cm}^{-1}$ region were determined. The experiment was supported by an anharmonic analysis based on Möller-Plesset perturbation theory and density functional theory level of theory, including the hybrid B2PLYP functional. Assignments of numerous bands observed in the liquid phase were proposed basing on potential energy distribution calculations and a comparison of experimental and simulated spectra was presented. The inaccuracy of static calculations in the reproduction of experimental spectrum in the $\mathrm{C}-\mathrm{H}$ stretching region has been observed and explained by the rotation of methyl group. A vibrational spectrum was therefore calculated by the use of Car-Parinello molecular dynamics method for a better simulation of experimental spectrum.

DOI: 10.12693 /APhysPolA.124.115

PACS: $78.20 . \mathrm{Bh}, 78.20 . \mathrm{Ci}, 78.30 . \mathrm{cb}$

\section{Introduction}

N-methylpyrrole is a substituted heterocyclic aromatic compound which was widely studied with numerous methods. Infrared investigations were rather scarce, starting from older studies in the 70's [1] to recent IR vapor and absorption studies [2] and fluorescence investigations as well [3]. Similarly as its more popular peer, pyrrole, N-methylpyrrole has been subject of a growing number of biochemical investigations, with newest studies focused on polymers and biopolymers $[4,5]$. Yet its spectroscopic properties in liquid phase have not drawn much attention.

The main goal of this work was to study vibrational spectra of N-methylpyrrole in the neat liquid phase, which is often more desired in industrial and other practical applications than the spectrum in gas phase or isolated molecule. The major difficulty encountered in the process of determination of these data is the high absorbance of pure liquid in the MIR region. This imposes the use of quantitative thin-film transmission recording techniques, with custom assembled cells of thicknesses in the range of few micrometers. Experimental data were supported by the Möller-Plesset perturbation theory (MP2) and density functional theory (DFT) harmonic and anharmonic calculations and also CarParinello molecular dynamics (CPMD) calculations, with the hope to obtain a further insight into factors determining the vibrational spectra of the compound. The results of investigation reported here are also the necessary basis for the upcoming studies of the high-frequency dielectric properties of N-methylpyrrole.

\section{Experimental}

Thin film transmission spectra were recorded on a FTIR Bruker IFS 113v spectrometer. Resolution was

\footnotetext{
*corresponding author; e-mail: krzysztof .bec@chem. uni.wroc.pl
}

maintained on the level of $0.3 \mathrm{~cm}^{-1}$ and the BlackmanHarris 3-Term apodization function was employed. The reference spectrum (empty chamber) was measured twice - before and after the sample measurement, to minimize the effect of possible drift. The MIR spectra were recorded in $\mathrm{KBr}$ cells assembled for the purpose of this work from windows polished to high flatness, monitored in sodium light on a glass optical flat. The spacers were prepared out of teflon and silver foils. The geometrical parameters of the cell cavity were determined by fitting the experimental interference spectrum of the empty cell with the theoretical ones, using the procedure based on the earlier derived algorithm ([6] and references cited therein).

$\mathrm{N}$-methylpyrrole exhibits several very strong bands in the MIR region. To ensure a reasonable accuracy of the spectral measurements, extremely thin cells had to be used. Cells with following parameters (Table I) were assembled for the purpose of this study in the MIR and NIR region.

TABLE I

NIR and MIR cell parameters used for neat liquid $\mathrm{N}$-methylpyrrole spectra measurements.

\begin{tabular}{c|c|c|c}
\hline \hline $\begin{array}{c}\text { Measurement } \\
\text { range }\left[\mathrm{cm}^{-1}\right]\end{array}$ & $\begin{array}{c}\text { Cell } \\
\text { material }\end{array}$ & $d^{a}$ & $\Delta^{b}$ \\
\hline $12500-4000$ & quartz & $1.0 \mathrm{~cm}$ & - \\
& & $3.28 \mu \mathrm{m}$ & $0.69 \mu \mathrm{m}$ \\
$5000-560$ & $\mathrm{KBr}$ & $2.23 \mu \mathrm{m}$ & $0.71 \mu \mathrm{m}$ \\
& & $2.45 \mu \mathrm{m}$ & $1.18 \mu \mathrm{m}$ \\
\hline
\end{tabular}

\footnotetext{
${ }^{\mathrm{a}} d$ - mean thickness of the cell [8];
}

b $\Delta$ - wedge parameter of the cell [8]

In the NIR region the spectra were measured on a Varian Cary 5 spectrophotometer. The Raman spectrum was recorded on a Nicolet Magna 860 FT-IR/Raman spectrometer.

$\mathrm{N}$-methylpyrrole (Sigma-Aldrich) was dried and stored over molecular sieves under nitrogen. The density at 
$298 \mathrm{~K}$ was $0.9043 \mathrm{~g} \mathrm{~cm}^{-3}$ and the refractive index at sodium $D$ line was 1.4859 . The measurements were carried out at $298 \pm 0.1 \mathrm{~K}$.

\section{Data processing}

From the thin film transmission spectra in whole measured region, the spectrum of both components of the complex refractive index

$$
\hat{n}(\nu)=n(\nu)+\mathrm{i} k(\nu)
$$

was determined following the procedure described previously [7]; $\mathrm{i}=\sqrt{-1}$ and $\nu$ denotes wave numbers $\left[\mathrm{cm}^{-1}\right]$ throughout this work. The spectrum was processed as a whole from 12500 to $560 \mathrm{~cm}^{-1}$. The digitization interval in the NIR and MIR regions was adjusted to $0.5 \mathrm{~cm}^{-1}$ by numerical interpolation. Firstly the experimental $k(\nu)$ spectrum was corrected for dispersion distortion. The reference point needed for the preliminary processing of data with the use of dispersion distortion correction procedure was taken at the sodium $D$ line $(589.6 \mathrm{~nm})$; this ensures a very good accuracy for the $k(\nu)$ spectrum. At the second stage, the $n(\nu)$ spectrum was calculated using the modified Kramers-Kronig procedure [7].

As mentioned earlier, the spectra of the complex refractive index are needed for the determination of high frequency dielectric properties of the studied liquid, which are in progress. Furthermore, a discussion of the absorptive properties of the liquid can be based only on the absorption index spectrum $k(\nu)$, since the transmission spectra of thin layers are strongly distorted [8].

\section{Results and discussion}

$$
\text { 4.1. NIR spectra }
$$

In order to obtain reliable spectra of the complex refractive index in the entire spectral region, particularly in the MIR range, the spectra in the visible and NIR range had to be measured, too [7]. The studied liquid is completely transparent in the visible range, hence $k(\nu)=0$ in this region. The complete spectrum of the complex refractive index in the measured NIR range (12500-3700 $\mathrm{cm}^{-1}$ ), covering the first and second overtone regions, is presented in Fig. 1.

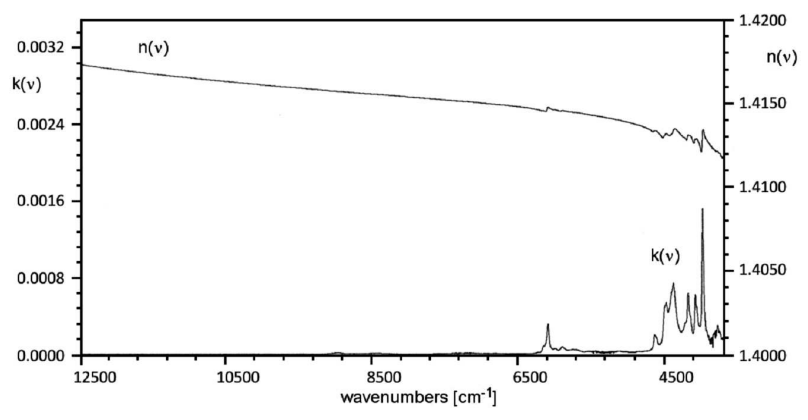

Fig. 1. Complex refractive index spectrum of N-methylpyrrole in $12500-3700 \mathrm{~cm}^{-1}$ range.

As can be seen, the NIR bands are intrinsically extremely weak except for bands in the region 6000$5600 \mathrm{~cm}^{-1}$. As concerns band positions, they are of no much help for the assignment process, since numerous summation or difference bands match the observed experimental peak positions. In general, the range between $6000-5600 \mathrm{~cm}^{-1}$ reflects well the doubled 3000 $2800 \mathrm{~cm}^{-1}$ region. The analysis of overtones for the studied molecule was not the aim of this work and will not be presented here. However the $\hat{n}(\nu)$ spectrum had to be determined in the NIR region, since its knowledge is essential for an accurate determination of the $\hat{n}(\nu)$ spectrum in the MIR region [7].

\subsubsection{General features}

\subsection{MIR spectra}

The exemplary transmission spectrum is shown in Fig. 2, while the FT-Raman spectrum is presented in Fig. 3. The spectrum of the complex refractive index of the studied liquid in the upper MIR range (3700$\left.2000 \mathrm{~cm}^{-1}\right)$ is depicted in Fig. 4 and in the lower MIR range $\left(2000-560 \mathrm{~cm}^{-1}\right)$ in Fig. 5 .

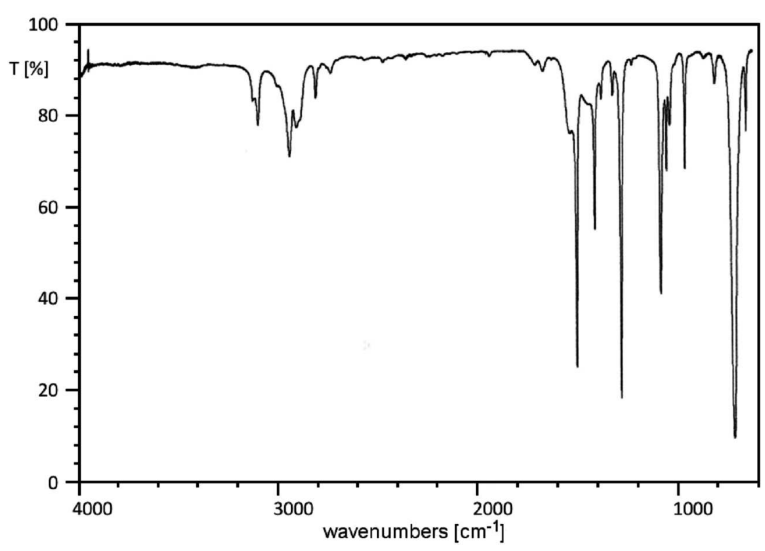

Fig. 2. Exemplary thin-film transmission spectrum of liquid $\mathrm{N}$-methylpyrrole measured in $\mathrm{KBr}$ cell $(d=$ $3.23 \mu \mathrm{m}, \Delta=0.71 \mu \mathrm{m})$.

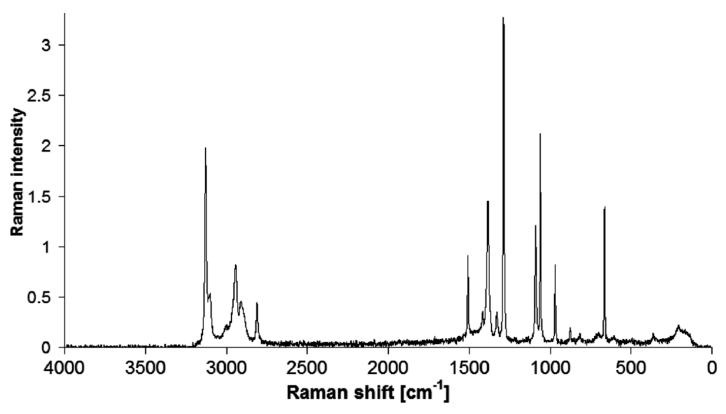

Fig. 3. Raman spectrum of liquid N-methylpyrrole.

The spectral data will be discussed in detail below, let us only notice here that generally in the $k(\nu)$ spectrum the bands are moderately weak, with the most prominent feature at $724.4 \mathrm{~cm}^{-1}$ reaching a maximum value of 0.6 . 4.2.2. DFT and MP2 calculation of vibrational spectra

Calculations of infrared spectra were carried out using the GAUSSIAN 09 package [9]. Geometry optimization 


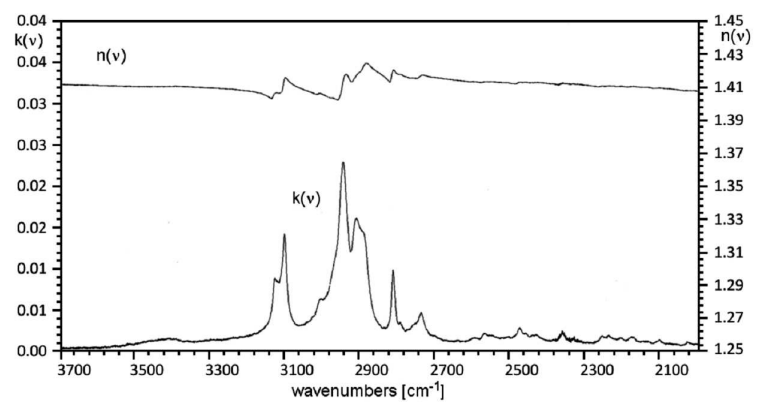

Fig. 4. Complex refractive index spectrum of $\mathrm{N}$-methylpyrrole in $3700-2000 \mathrm{~cm}^{-1}$ range.

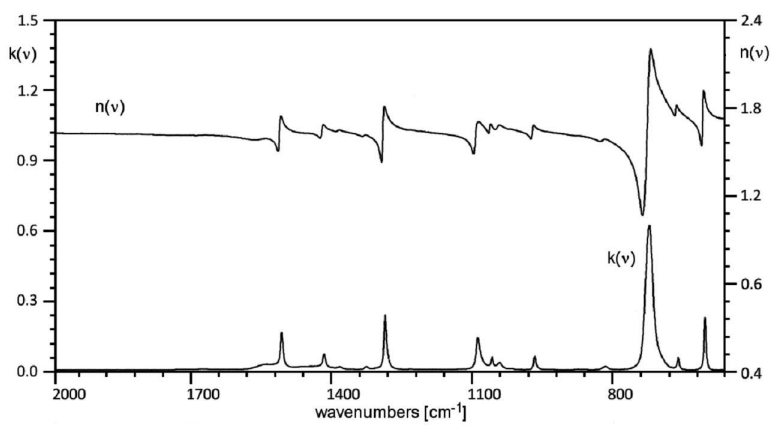

Fig. 5. Complex refractive index spectrum of $\mathrm{N}$-methylpyrrole in $2000-560 \mathrm{~cm}^{-1}$ range.

was performed and the wave numbers were calculated with the use of MP2 and DFT both at harmonic and anharmonic level. Based on recent studies [10] we used B2PLYP functional with N07D basis sets, as it is proposed in the literature as very accurate and valuable tool for anharmonic vibrational analysis. Table II presents calculated on a B2PLYP/N07D level geometrical parameters of molecule. The results reflect well the structural parameters obtained through gas electron diffraction and microwave experiments [11]. The atom numbering assumed for the purposes of this work is shown in Fig. 6 . Table III is showing the internal coordinates constructed for the normal coordinate analysis (NCA) calculations. The resulting potential energy distributions (PEDs) are presented in Table IV.

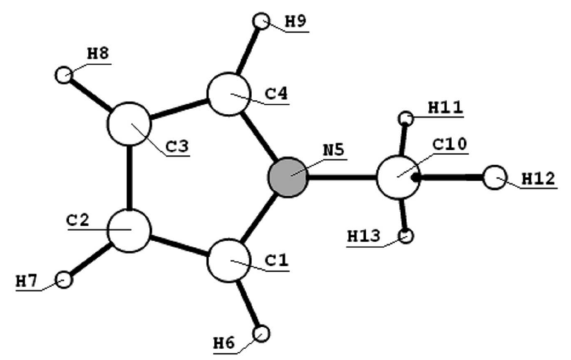

Fig. 6. Atom numbering in the N-methylpyrrole molecule.
TABLE II

Calculated structural parameters of the N-methylpyrrole molecule.

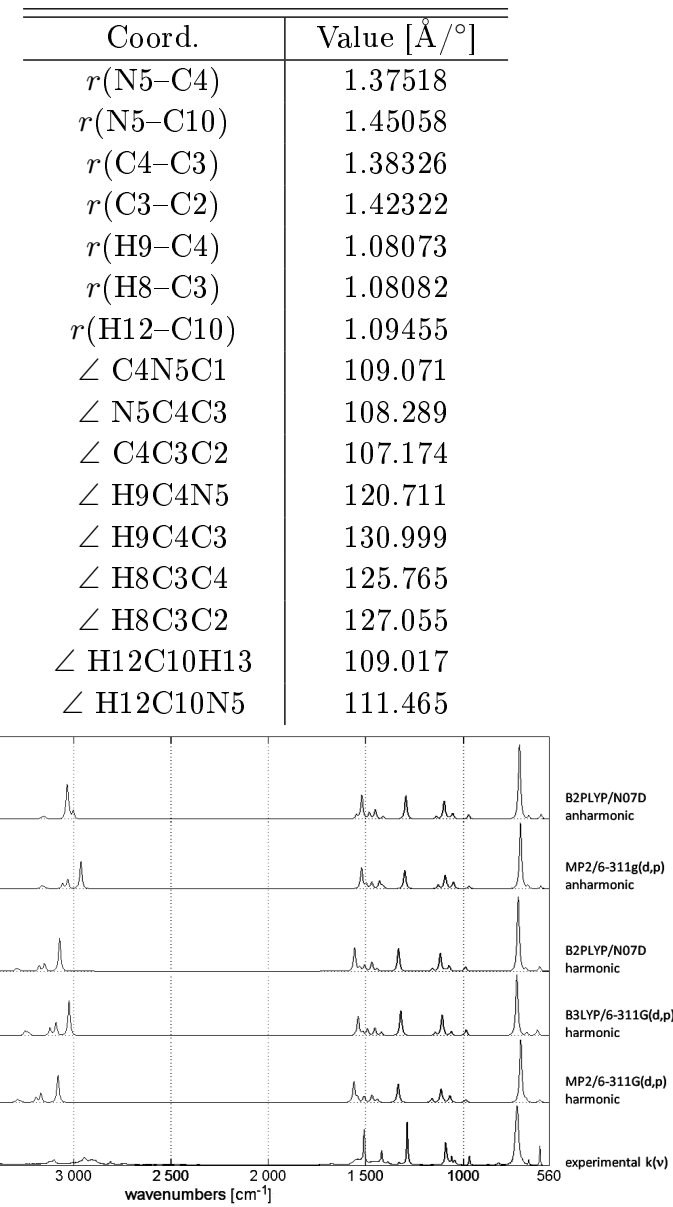

Fig. 7. Experimental and calculated spectra of $\mathrm{N}$-methylpyrrole in $4000-560 \mathrm{~cm}^{-1}$ range.

The theoretical spectra are presented in Fig. 7. In Figs. 8 and 9 amplified segments of the calculated spectra are presented for a better view of details. As the band model the Cauchy-Gauss product function was employed [12].

The identification of bands observed in liquid phase spectra, based on a thorough comparison of the experimental $k(\nu)$ spectrum, Raman spectrum and the simulated IR spectra are presented in Table V. The band assignment process was based mainly on anharmonic B2PLYP/N07D calculations. However also the harmonic and anharmonic MP2 and B3LYP calculations were used for comparison, and we have chosen to provide them for reference (Table V). The potential energy distribution was calculated using the Gar2ped package [13], with the internal coordinates constructed in accordance to $\mathrm{Pu}-$ lay [14]. The selection of modes was based on the dominant $P E D$ values.

Generally, as can be seen from Table V and Figs. 7-9, the anharmonic procedures give more accurate results 


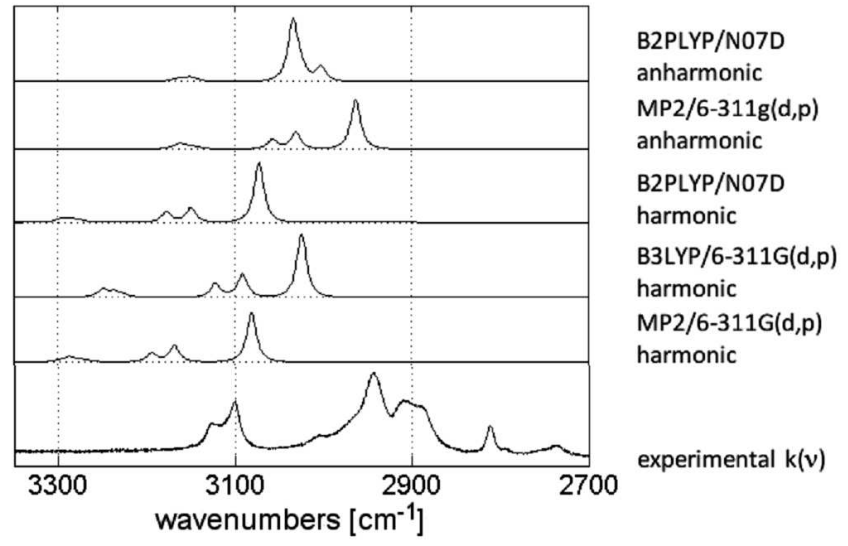

Fig. 8. Experimental and calculated spectra of $\mathrm{N}$-methylpyrrole in $3350-2700 \mathrm{~cm}^{-1}$ range.

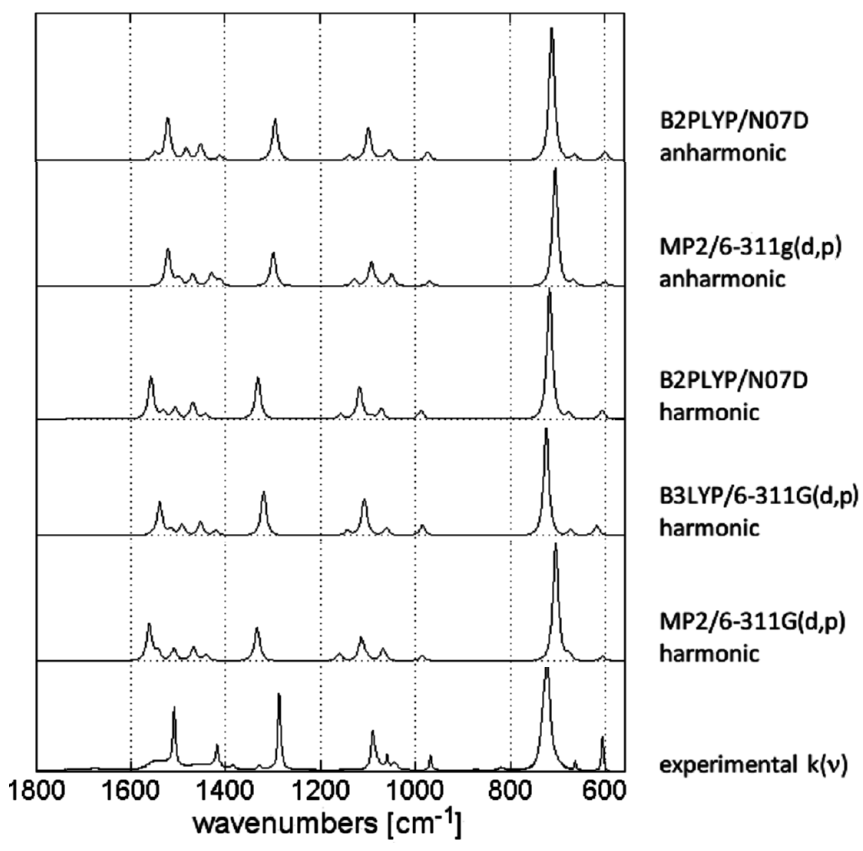

Fig. 9. Experimental and calculated spectra of $\mathrm{N}$-methylpyrrole in $1800-560 \mathrm{~cm}^{-1}$ range.

than the harmonic ones. As concerns the lower MIR range $\left(2000-560 \mathrm{~cm}^{-1}\right)$ the $\mathrm{B} 2 \mathrm{PLYP} / \mathrm{N} 07 \mathrm{D}$ method gives good results, notably for the $\mathrm{C}-\mathrm{C}, \mathrm{C}-\mathrm{N}$ stretching and $\mathrm{C}-\mathrm{H}$ in plane bending modes. It is however surprising that in contrary to MP2/6-311G(d,p) calculations, the B2PLYP/N07D anharmonic approximation reverses the sequence of the antisymmetric and symmetric methyl stretching modes (Table V). Other ranges of N-methylpyrrole spectrum were clearly better reproduced by the anharmonic B2PLYP/N07D calculations, especially the $1500 \mathrm{~cm}^{-1}$ region (Fig. 9). Basing on these results we propose different assignments in this region in comparison with earlier studies [3].

Still, for all applied methods the agreement with experimental N-methylpyrrole spectrum in the upper MIR range (stretching modes) is poor, both in raw frequen- cies and even more in relative intensities, resulting in overall different shape of simulated spectrum. The described effect was shown in our earlier studies [15, 16]. However here in case of $\mathrm{N}$-methylpyrrole it is much more noticeable, making identification of $\mathrm{C}-\mathrm{H}$ stretching bands particularly difficult. The reason for this inaccuracy in spectra reproduction is most probably due to relatively free rotation of methyl group, as the barrier to internal rotation of $\mathrm{CH}_{3}$ group is indeed very small for N-methylpyrrole molecule $[17,18]$. Such effect cannot be properly simulated by static calculations. Therefore we applied quantum dynamic calculations to achieve better agreement between simulated and experimental spectra.

\subsubsection{CPMD calculations}

CPMD [19] simulations were performed. The molecular dynamics simulations were carried out using the efficient Car-Parrinello propagation scheme [20] as implemented in the CPMD program package version 3.12 .2 [21].

Following the initial equilibration period ( $c a .25000$ steps $-2 \mathrm{ps}$ ), where each degree of freedom had a separate Nose-Hoover-chain (NHC) thermostat, data were collected over trajectories spanning 550000 steps (around $40 \mathrm{ps}$ ). During the initial equilibration period each atom was thermalized (difference from the desired temperature was not more than $5 \%$ ) before start of proper run with only one NHC thermostat. A kinetic energy cutoff of $120 \mathrm{Ry}$ was used for the electron plane-wave basis and $\Gamma$-point sampling of the Brillouin zone. The Troullier and Martin pseudopotentials [22] and the PerdewBurke-Ernzerhof (PBE) exchange and correlation functional [23] were applied. The simulations were performed in the canonical ensemble at $298 \mathrm{~K}$. To control the temperature of the system the NHC thermostat [24, 25] was turned on (to control kinetic energy of the nuclei as well as the fictitious energy of the orbitals) and set at a frequency of $3000 \mathrm{~cm}^{-1}$. A molecular dynamics time step of $\delta t=3$ a.u. (around $0.07 \mathrm{fs}$ ) was used for the integration of the Car-Parrinello equations of motion using fictitious mass parameters for the orbitals of 400 a.u. together with the proper atomic masses. The supercell was a cubic box of $14.0 \AA$ in length, and cluster boundary conditions [26] were applied to properly treat the isolated system.

The resulting vibrational spectrum in the $\mathrm{C}-\mathrm{H}$ stretching range obtained by CPMD calculations is presented in Fig. 10.

As can be seen, in the $\mathrm{C}-\mathrm{H}$ stretching region the shape of vibrational spectrum of $\mathrm{N}$-methylpyrrole obtained with CPMD calculations resembles much better the shape of experimental spectrum, although the results are obtained for isolated molecules. At present, we are however unable to explain neither the "compression" of the CPMD spectrum, nor ascribe particular modes to the calculated peaks. The results show however the need to use molecular dynamics methods to elucidate vibrational spectra of N-methylpyrrole and similar molecules. 


\subsubsection{Identification of bands in MIR region}

The final band identification was based on methods described in Sect. 4.2.2. In the $3350-2700 \mathrm{~cm}^{-1}$ we observe numerous bands of which only few seem to stem from fundamentals. As stated earlier, the agreement between experimental and simulated spectra is here significantly lower than in other of investigated regions. However, with the aid of spectra predicted on various levels of theory, the assignment of main bands was possible. The ring $\mathrm{C}-\mathrm{H}$ modes are located over $3100 \mathrm{~cm}^{-1}\left(3126.0 \mathrm{~cm}^{-1}\right.$ and $\left.3099.4 \mathrm{~cm}^{-1}\right)$, while methyl $\mathrm{C}-\mathrm{H}$ stretching modes are in $2942.2 \mathrm{~cm}^{-1}$ and $2910.1 \mathrm{~cm}^{-1}$ (antisymmetric stretching) and $2811.5 \mathrm{~cm}^{-1}$ (symmetric stretching), respectively. All bands examined here are notably weak.

\section{TABLE III}

Internal coordinates constructed for the N-methylpyrrole molecule.

\begin{tabular}{|c|c|c|c|}
\hline Coord. no. & Definition & Coord. no. & Definition \\
\hline 1 & $\mathrm{C} 1-\mathrm{C} 2$ str. & 18 & $\mathrm{~N} 5-\mathrm{C} 10\left(\mathrm{H}_{3}\right)$ in plane bend \\
\hline 2 & C1-N5 str. & 19 & $\mathrm{~N} 5-\mathrm{C} 10\left(\mathrm{H}_{3}\right)$ out-of-plane bend \\
\hline 3 & $\mathrm{C} 1-\mathrm{H} 6$ str. & 20 & $\mathrm{C} 1-\mathrm{H} 6$ in plane bend \\
\hline 4 & $\mathrm{C} 2-\mathrm{C} 3$ str. & 21 & C1-H6 out-of-plane bend \\
\hline 5 & $\mathrm{C} 2-\mathrm{H} 7$ str. & 22 & $\mathrm{C} 2-\mathrm{H} 7$ in plane bend \\
\hline 6 & $\mathrm{C} 3-\mathrm{C} 4$ str. & 23 & $\mathrm{C} 2-\mathrm{H} 7$ out-of-plane bend \\
\hline 7 & $\mathrm{C} 3-\mathrm{H} 8$ str. & 24 & $\mathrm{C} 3-\mathrm{H} 8$ in plane bend \\
\hline 8 & $\mathrm{C} 4-\mathrm{N} 5$ str. & 25 & C3-H8 out-of-plane bend \\
\hline 9 & C5-H10 str. & 26 & $\mathrm{C} 4-\mathrm{H} 9$ in plane bend \\
\hline 10 & $\mathrm{~N} 5-\mathrm{C} 10\left(\mathrm{H}_{3}\right)$ str. & 27 & C4-H9 out-of-plane bend \\
\hline 11 & C10-H11 str. $\left(\mathrm{CH}_{3}\right)$ & 28 & $\mathrm{CH}_{3}$ symm. def. \\
\hline 12 & $\mathrm{C} 10-\mathrm{H} 12$ str. $\left(\mathrm{CH}_{3}\right)$ & 29 & $\mathrm{CH}_{3}$ asym. def. \\
\hline 13 & C10-H13 str. $\left(\mathrm{CH}_{3}\right)$ & 30 & $\mathrm{CH}_{3}$ asym. def.' \\
\hline 14 & ring deformation & 31 & $\mathrm{CH}_{3}$ wagg. \\
\hline 15 & ring deformation' & 32 & $\mathrm{CH}_{3}$ wagg.' \\
\hline 16 & ring torsion & 33 & $\mathrm{CH}_{3}$ torsion \\
\hline 17 & ring torsion' & & \\
\hline
\end{tabular}

PED ( $\geq 5 \%$ ) table for N-methylpyrrole based on B2PLYP/N07D calculations.

\begin{tabular}{|c|c|c|c|c|c|c|c|c|c|c|}
\hline Harmonic & Anharmonic & \multirow{2}{*}{\multicolumn{9}{|c|}{ Modes (\%) }} \\
\hline \multicolumn{2}{|c|}{ frequency $\left[\mathrm{cm}^{-1}\right]$} & & & & & & & & & \\
\hline 92.30 & 72.27 & $33(87)$ & $\begin{array}{ll}-31 & (8)\end{array}$ & & & & & & & \\
\hline 187.03 & 196.734 & $19(97)$ & & & & & & & & \\
\hline 360.23 & 361.666 & $18(85)$ & $31 \quad(5)$ & & & & & & & \\
\hline 606.94 & 599.667 & $17(83)$ & $-19(11)$ & & & & & & & \\
\hline 610.68 & 612.798 & $16(85)$ & $-25 \quad(6)$ & $23 \quad(6)$ & & & & & & \\
\hline 671.29 & 669.764 & $21(44)$ & $-27(44)$ & & & & & & & \\
\hline 677.23 & 663.072 & $14(43)$ & $-10(37)$ & $-2 \quad(6)$ & $-8 \quad(6)$ & & & & & \\
\hline 717.78 & 711.384 & $27(23)$ & $21(23)$ & $23(23)$ & $25(23)$ & $17 \quad(6)$ & & & & \\
\hline 804.19 & 801.886 & $21(23)$ & $27(23)$ & $-23(22)$ & $-25(22)$ & $17(10)$ & & & & \\
\hline 844.01 & 859.81 & $25(39)$ & $-23(39)$ & $-16(12)$ & & & & & & \\
\hline 887.31 & 875.937 & $15(90)$ & & & & & & & & \\
\hline 988.67 & 972.687 & $14(34)$ & $22(17)$ & $-24(17)$ & $2(12)$ & $8(12)$ & $10 \quad(8)$ & & & \\
\hline 1072.08 & 1054.081 & $31(25)$ & $24(10)$ & $22(10)$ & $2(10)$ & $-8(10)$ & $32 \quad(8)$ & $-6(7)$ & $1(7)$ & \\
\hline 1091.33 & 1072.385 & $4(52)$ & $-22(14)$ & $24(14)$ & $14 \quad(5)$ & & & & & \\
\hline 1117.11 & 1096.966 & $31(26)$ & $20(14)$ & $26(14)$ & $32 \quad(9)$ & $-22 \quad(8)$ & $-24 \quad(8)$ & $-1(6)$ & $6(6)$ & \\
\hline 1118.01 & 1098.51 & $26(26)$ & $-20(26)$ & $6(12)$ & $1(12)$ & & & & & \\
\hline 1157.14 & 1137.919 & $32(65)$ & $-31(22)$ & $-30 \quad(6)$ & & & & & & \\
\hline 1305.28 & 1280.169 & $26(27)$ & $20(27)$ & $24(19)$ & $22(19)$ & & & & & \\
\hline 1332.10 & 1294.597 & $10(39)$ & $-6(10)$ & $-1(10)$ & $-4 \quad(8)$ & $14 \quad(7)$ & $-8 \quad(6)$ & $-2(6)$ & & \\
\hline 1423.03 & 1381.2 & $8(31)$ & $-2(31)$ & $29 \quad(9)$ & $-15 \quad(7)$ & $-18 \quad(6)$ & $31 \quad(6)$ & & & \\
\hline 1441.82 & 1409.712 & $4(33)$ & $-1(17)$ & $-6(17)$ & $-24(11)$ & $22(11)$ & $-14(10)$ & & & \\
\hline 1469.08 & 1451.128 & $28(81)$ & $10 \quad(9)$ & & & & & & & \\
\hline 1506.37 & 1481.795 & $30(66)$ & $-29(22)$ & $32 \quad(7)$ & & & & & & \\
\hline 1530.97 & 1547.73 & $29(55)$ & $30(18)$ & $\begin{array}{ll}-31 & (9)\end{array}$ & & & & & & \\
\hline 1557.64 & 1520.311 & $20(16)$ & $-26(16)$ & $-2(14)$ & $-8(14)$ & $1 \quad(9)$ & $6 \quad(9)$ & $10(7)$ & $-28(7)$ & $14(5)$ \\
\hline 1560.70 & 1524.623 & $6(31)$ & $-1(31)$ & $22 \quad(9)$ & $24 \quad(9)$ & $-26 \quad(5)$ & $-20 \quad(5)$ & & & \\
\hline 3072.16 & 3033.713 & $12(59)$ & $11(20)$ & $13(20)$ & & & & & & \\
\hline 3148.97 & 3002.097 & $12(41)$ & $-11(29)$ & $-13(29)$ & & & & & & \\
\hline 3176.60 & 3025.13 & $13(50)$ & $-11(50)$ & & & & & & & \\
\hline 3274.45 & 3144.656 & $7(36)$ & $-5(36)$ & $-9(13)$ & $3(13)$ & & & & & \\
\hline 3283.56 & 3150.627 & $9(27)$ & $3(27)$ & $-5(23)$ & $-7(23)$ & & & & & \\
\hline 3294.30 & 3160.161 & $9(36)$ & $-3(36)$ & $7(13)$ & $-5(13)$ & & & & & \\
\hline 3301.84 & 3170.258 & $5(27)$ & $7(27)$ & $3(23)$ & $9(23)$ & & & & & \\
\hline
\end{tabular}


Band identification in liquid N-methylpyrrole $k(\nu)$ spectrum.

\begin{tabular}{|c|c|c|c|c|c|c|c|}
\hline \multirow[t]{2}{*}{$\nu_{\exp }\left[\mathrm{cm}^{-1}\right]$} & \multirow[t]{2}{*}{$k_{\max }$} & \multicolumn{3}{|c|}{$\nu_{\text {calc }}\left[\mathrm{cm}^{-1}\right]$ harmonic } & \multicolumn{2}{|c|}{$\nu_{\text {calc }}\left[\mathrm{cm}^{-1}\right]$ anharmonic } & \multirow[t]{2}{*}{ Assignment } \\
\hline & & $\begin{array}{r}\text { MP2/ } \\
6-31\end{array}$ & $\begin{array}{l}\text { B3LYP/ } \\
\mathrm{g}(\mathrm{d}, \mathrm{p})\end{array}$ & $\begin{array}{l}\text { B2PLYP/ } \\
\text { N07D }\end{array}$ & $\begin{array}{c}\text { MP2/ } \\
6-311 G(d, p)\end{array}$ & $\begin{array}{l}\text { B2PLYP/ } \\
\text { N07D }\end{array}$ & \\
\hline 3126.0 & $0.0062(2)$ & 3287 & 3248 & 3294 & 3160 & 3159 & $\mathrm{C}-\mathrm{H}$ (ring) str. \\
\hline 3099.4 & $0.0113(5)$ & 3277 & 3236 & 3284 & 3151 & 3150 & $\mathrm{C}-\mathrm{H}$ (ring) str. \\
\hline 3003.3 & $0.0049(2)$ & - & - & - & - & - & - \\
\hline 2965.3 & $0.0074(3)$ & - & - & - & - & - & - \\
\hline 2942.2 & $0.0149(8)$ & 3193 & 3121 & 3176 & 3056 & 3025 & $\mathrm{CH}_{3}$ str. asym.' \\
\hline 2910.1 & $0.0123(6)$ & 3168 & 3091 & 3149 & 3030 & 3002 & $\mathrm{CH}_{3}$ str. asym. \\
\hline 2886.2 & $0.071(2)$ & - & - & - & - & - & - \\
\hline 2849.9 & $0.00217(7)$ & - & - & - & - & - & - \\
\hline 2811.5 & $0.0073(3)$ & 3081 & 3024 & 3072 & 2963 & 3033 & $\mathrm{CH}_{3}$ str. symm. \\
\hline 2791.8 & $0.00185(4)$ & - & - & - & - & - & - \\
\hline 2774.9 & $0.00125(5)$ & - & - & - & - & - & - \\
\hline 2757.6 & $0.00122(4)$ & - & - & - & - & - & - \\
\hline 2735.9 & $0.0036(1)$ & - & - & - & - & - & - \\
\hline 1541.1 & $0.0027(1)$ & 1542 & 1515 & 1530 & 1496 & 1547 & $\mathrm{CH}_{3}$ asym. def., $\mathrm{CH}_{3}$ asym. def.' \\
\hline 1508.6 & $0.170(9)$ & 1561 & 1539 & 1558 & 1522 & 1520 & $\mathrm{C}-\mathrm{H}$ in plane bend. \\
\hline 1448.7 & $0.0205(9)$ & 1509 & 1492 & 1506 & 1470 & 1482 & $\mathrm{CH}_{3}$ asym. def'. \\
\hline 1414.5 & $0.066(3)$ & 1468 & 1453 & 1469 & 1429 & 1451 & $\mathrm{CH}_{3}$ sym. def. \\
\hline 1384.0 & $0.0105(4)$ & 1441 & 1420 & 1442 & 1413 & 1410 & $\mathrm{C}$ (ring) $-\mathrm{N}$ str., $\mathrm{C}-\mathrm{C}$ str. \\
\hline 1327.7 & $0.0148(4)$ & - & - & - & - & - & - \\
\hline 1287.4 & $0.27(2)$ & 1334 & 1320 & 1332 & 1300 & 1294 & $\mathrm{~N}-\mathrm{C}\left(\mathrm{H}_{3}\right)$ str., $\mathrm{C}-\mathrm{C}$ str. \\
\hline 1233.5 & $0.0053(1)$ & - & - & - & - & - & - \\
\hline 1089.1 & $0.164(8)$ & 1116 & 1108 & 1118 & 1094 & 1099 & $\mathrm{C}-\mathrm{H}$ in plane bend. \\
\hline 1059.9 & $0.057(3)$ & 1101 & 1078 & 1091 & 1081 & 1072 & $\mathrm{C}-\mathrm{C}$ str. \\
\hline 1043.4 & $0.034(3)$ & 1069 & 1061 & 1072 & 1050 & 1054 & $\mathrm{CH}_{3}$ wagg., $\mathrm{C}-\mathrm{H}$ in plane bend. \\
\hline 1017.7 & $0.0041(2)$ & - & - & - & - & - & - \\
\hline 968.4 & $0.0704(3)$ & 986 & 985 & 988 & 969 & 972 & $\mathrm{C}-\mathrm{H}$ in plane bend., ring def. \\
\hline 818.6 & $0.0195(9)$ & 763 & 818 & 804 & 791 & 802 & $\mathrm{C}-\mathrm{H}$ out-of-plane bend. \\
\hline 724.4 & $0.60(4)$ & 705 & 725 & 718 & 706 & 711 & $\mathrm{C}-\mathrm{H}$ out-of-plane bend. \\
\hline 719.1 & $0.107(4)$ & - & - & - & - & - & - \\
\hline 663.3 & $0.063(2)$ & 678 & 673 & 677 & 667 & 663 & ring deformation, $\mathrm{N}-\mathrm{C}\left(\mathrm{H}_{3}\right)$ str. \\
\hline 606.3 & $0.27(1)$ & 605 & 618 & 607 & 601 & 600 & ring torsion' \\
\hline
\end{tabular}

In the $1800-900 \mathrm{~cm}^{-1}$ range the spectrum is populated by $\mathrm{CH}_{3}$ group deformations, $\mathrm{C}-\mathrm{C}$ and $\mathrm{C}-\mathrm{N}$ stretching modes, by in-plane and out-of-plane $\mathrm{C}-\mathrm{H}$ bendings and ring deformations. Two dominant peaks here are at $1508.6 \mathrm{~cm}^{-1}(\mathrm{C}-\mathrm{H}$ in plane bend with $\mathrm{C}$ (ring) $-\mathrm{N}$ stretching) and at $1287.4 \mathrm{~cm}^{-1}\left(\mathrm{~N}-\mathrm{C}\left(\mathrm{H}_{3}\right)\right.$ stretching with $\mathrm{C}-\mathrm{C}$ stretching).

The $900-560 \mathrm{~cm}^{-1}$ range is a relatively uncomplicated region, where four fundamental bands can be identified. The most intensive $724.4 \mathrm{~cm}^{-1}$ band is assigned to $\mathrm{C}-\mathrm{H}$ out of plane bending mode. The band of ring torsion's mode is located at $606.3 \mathrm{~cm}^{-1}$ and is second in intensity in this region. The other less intensive bands are at $818.6 \mathrm{~cm}^{-1}$ and $724.4 \mathrm{~cm}^{-1}$ (C-H out-of-plane bending) and also at $663.3 \mathrm{~cm}^{-1}$ (ring deformation with $\mathrm{N}-\mathrm{C}\left(\mathrm{H}_{3}\right)$ stretching).

The ring deformation and $\mathrm{C}-\mathrm{H}$ deformation bands are shifted to lower frequencies in comparison with pyrrole spectrum [27]. It is likely caused by the inherence of $\mathrm{CH}_{3}$ group.

The results generally correspond with earlier studies, based on harmonic calculations and force constants scaling $[2,3]$. With the aid of improved computational methods and comparison of few basis sets and methods it was possible to amend the assignments of a few minor bands.

\section{Summary}

Quantitative NIR-MIR (12500-560 $\mathrm{cm}^{-1}$ range) transmission measurements of N-methylpyrrole in the neat liquid phase were performed and the spectrum of the complex refractive index was determined. The absorption bands of neat liquid were found of moderate strength, not exceeding 0.6 at the absorption index scale. The NIR bands are generally very weak. FT/Raman spectra were also measured for referential comparison. A detailed anharmonic vibrational analysis was performed, with the use of several computational methods and basis sets. The observed spectrum of neat liquid was accurately reproduced in the lower MIR range $\left(2000-560 \mathrm{~cm}^{-1}\right)$. The $\mathrm{C}-\mathrm{H}$ stretching region however was found to be poorly reproduced by static calculations, most probably due to free rotation of methyl group. The CPMD calculations, taking into account the $\mathrm{CH}_{3}$ group rotation, allowed to obtain a better agreement of simulated spectra with experimental one in the bothersome $\mathrm{C}-\mathrm{H}$ region. The final identification band procedure was based on the natural coordinates analysis and calculated potential energy distributions. Basing on these data, the identification of numerous IR and Raman bands of liquid N-methylpyrrole was performed, with a proposal of new assignments for bands in the $1500 \mathrm{~cm}^{-1}$ region. 

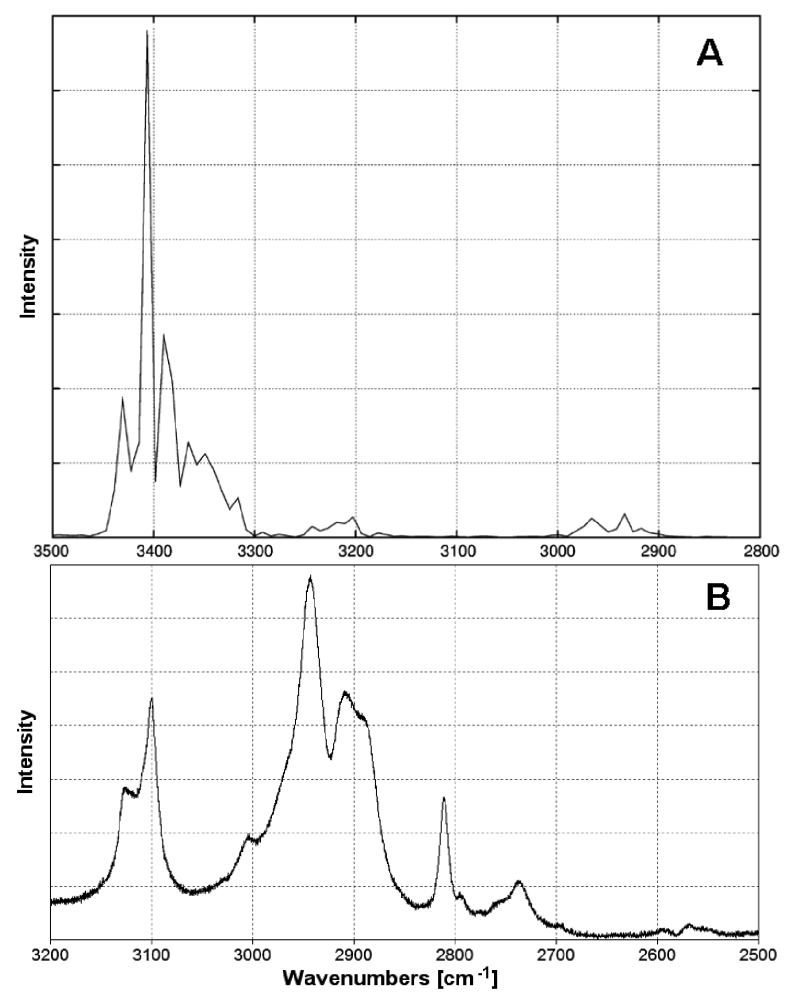

Fig. 10. Vibrational spectrum of N-methylpyrrole in the $3500-2800 \mathrm{~cm}^{-1}$ range obtained by the use of CPMD calculations (A). For comparison, the experimental spectrum was shown (B) in the corresponding spectral range.

\section{References}

[1] D.W. Scott, J. Mol. Spectrosc. 37, 77 (1971).

[2] T.J. Dines, L.D. MacGregor, C.H. Rochester, J. Colloid. Interf. Sci. 245, 221 (2002).

[3] N. Biswas, S. Wategaonkar, J.G. Philis, Chem. Phys. 293, 99 (2003).

[4] M.I. Redondo, E. Sanchez, de la Blanca, M.V. Garcıa, M.A. Raso, J. Tortajada, M.J. Gonzalez-Tejera, Synthetic Met. 122, 431 (2001).

[5] B. Teixeira-Diasa, C. Alemán, F. Estrany, D.S. Azambuja, E. Armelin, Electrochim. Acta 56, 5836 (2011).

[6] W. Wrzeszcz, A.S. Muszyński, J.P. Hawranek, Comp. Chem. 22, 101 (1998).
[7] J.P. Hawranek, A.S. Muszyński, Comp. Chem. 22, 95 (1998).

[8] J.P. Hawranek, P. Neelakantan, R.P. Young, R.N. Jones, Spectrochim. Acta 32A, 75 (1976).

[9] Gaussian 09, Revision A.02, Gaussian Inc., Wallingford CT, 2009.

[10] M. Biczysko, P. Panek, G. Scalmani, J. Bloino, V. Barone, J. Chem. Theory Comput. 6, 2115 (2010).

[11] H. Takeuchi, K. Inoue, J. Enmi, T. Hamada, T. Shibuya, S. Konaka, J. Mol. Struct. 567-568, 107 (2001).

[12] J.P. Hawranek, Acta Phys. Pol. A 40, 811 (1971).

[13] J.M.L. Martin, C. Van Alsenoy, GAR2PED, University of Antwerp, 1995.

[14] P. Pulay, G. Fogarasi, F. Pang, J.E. Boggs, J. Am Chem. Soc. 101, 2550 (1979).

[15] A.S. Muszyński, K.B. Beć, N. Michniewicz, W. Wrzeszcz, A. Mojak, J.P. Hawranek, J. Mol. Struct. 975, 205 (2010).

[16] K.B. Beć, A.S. Muszyński, N. Michniewicz, W. Wrzeszcz, A. Kotynia, J.P. Hawranek, Vib. Spectrosc. 55, 44 (2011).

[17] W. Arnold, H. Dreizler, H.D. Rudolph, Z. Naturforsch. Teil A 23, 301 (1968).

[18] J. Makarewicz, S. Huber, B. Brupbacher-Gatehouse, A. Bauder, J. Mol. Struct. 612, 117 (2002).

[19] R. Car, M. Parrinello, Phys. Rev. Lett. 55, 2471 (1985).

[20] D. Marx, J. Hutter, Ab Initio Molecular Dynamics: Basic Theory and Advanced Methods, Cambridge University Press, Cambridge 2009.

[21] CPMD program package; see http://www.cpmd.org .

[22] N. Troullier, J.L. Martins, Phys. Rev. B 43, 1993 (1991).

[23] J.P. Perdew, K. Burke, M. Ernzerhof, Phys. Rev. Lett. 77, 3865 (1996).

[24] S. Nosé, Mol. Phys. 52, 255 (1984).

[25] G.J. Martyna, M.E. Tuckerman, M.L. Klein, J. Chem. Phys. 97, 2635 (1992).

[26] R.W. Hockney, Methods Comput. Phys. 9, 136 (1970).

[27] B.I. Łydżba-Kopczyńska, K.B. Beć, J. Tomczak, J.P. Hawranek, J. Mol. Liq. 172, 34 (2012). 